\title{
Probabilistic safety assessment to determine the seismic fragility of NPP
}

\author{
Juraj Králik ${ }^{1, *}$ and Juraj Králik, jr. ${ }^{2}$ \\ ${ }^{1}$ FCE STU Bratislava, Department of Structural Mechanics, 81005 Bratislava, Slovak Republic \\ ${ }^{2}$ Academy of Fine Arts and Design in Bratislava, 81437 Bratislava, Slovak Republic
}

\begin{abstract}
This paper gives the results of the probabilistic analysis of the seismic resistance of nuclear power plant (NPP) structures. The seismic probabilistic safety assessment based on the requirements of the agency IAEA and US NRC are presented. On the base of the geophysical and seismological monitoring of locality the peak ground acceleration and the spectrum of the acceleration was defined for the return period $10^{4}$ years. There is showed summary of calculation models and calculation methods for the probability analysis of the structural safety considering load, material and model uncertainties. The numerical simulations were realized in the system ANSYS. The results from the safety analysis of the NPP structures with reactor VVER440 are presented.
\end{abstract}

\section{Introduction}

IAEA (International Atomic Energy Agency) set up a program [1] to give guidance to its member states on the many aspects of the safety of nuclear power reactors. The risk of the NPP performance from the point of the safety must be calculated by consideration of the impact of the all effects during plant operation. The PSA (Probabilistic Safety Analysis) is one from the effective methods to analyse the safety and reliability of the NPP. The international standard NUREG [2] defines the principal steps for the calculation of the risk of the NPP performance by LHS probabilistic method

- Accident frequency (systems) analysis

- Accident progression analysis

- Radioactive material transport (source term) analysis

- Offsite consequence analysis

- Risk integration.

The accidents caused by the earthquake even are the critical emergencies from the point of the NPP performance. This paper gives the experiences from the seismic analysis of the operated NPP in Slovakia [3-5]. The earthquake resistance analysis of NPP buildings in Slovakia were based on the recommends of international organization IAEA in Vienna to get international safety level of the nuclear power plants [5]. Seismic safety evaluation programs of the NPP structures should contain three important parts:

- The assessment of the seismic hazard as an external event, specific to the seismic-

* Corresponding author: juraj.kralik@stuba.sk 
tectonic and soil conditions of the site, and of the associated input motion;

- The safety analysis of the NPP resulting in an identification of the selected structures, systems and components appropriate for dealing with a seismic event with the objective of a safe shutdown;

- The evaluation of the plant specific seismic capacity to withstand the loads generated by such an event, possibly resulting in upgrading.

\section{Seismic safety methodology}

On the base of the experience from the re-evaluation programs in the membership countries IAEA in Vienna the seismic safety standard No. 28 was established at 2003 [1].

Seismic safety evaluation programs should contain three important parts

- The assessment of the seismic hazard as an external event, specific to the seismictectonic and soil conditions of the site, and of the associated input motion;

- The safety analysis of the NPP resulting in an identification of the SSSCs (Selected Structures, Systems and Components) appropriate for dealing with a seismic event with the objective of a safe shutdown;

- The evaluation of the plant specific seismic capacity to withstand the loads generated by such an event, possibly resulting in upgrading.

The individual seismic resistance re-evaluation of each building structure and each single component of NPP, technological equipment needs to be executed in the following way:

- seismic margin assessment of the equipment structure or component in the existing state, which means the seismic margin HCLPF (High Confidence Low Probability Failure) values determination in the existing state,

- projection of seismic modifications (measures), if necessary - if the seismic margin $H C L P F$ value is calculated > PGA (Peak Ground Acceleration),

- seismic margin assessment of the equipment structure or component in the so-called fixed state after the projected modifications were executed, which means the seismic margin $H C L P F$ values determination for this state.

The HCLPF seismic margin value is calculated for the $P G A$ for the review level of earthquake ( $\mathrm{RLE}=\mathrm{SL}-2)$ and it is defined mathematically as $95 \%$ probability that an earthquake will cause violation, SME (Seismic Margin Earthquake), in less than 5\% of cases.

\section{Probabilistic assessment}

Most problems concerning the reliability of building structures are defined today as a comparison of two stochastic values, loading effects $E$ and the resistance $R$, depending on the variable material and geometric characteristics of the structural element $[5,6]$. The probabilistic definition of the reliability condition is of the form

$$
R F=g(R, E)=R-E \geq 0
$$

where $R F$ is the reliability function. In the case of simulation methods, the failure probability is calculated from the evaluation of the statistical parameters and theoretical model of the probability distribution of the reliability function in the following form

$$
p_{f}=\frac{1}{N} \sum_{i=1}^{N} I\left[g\left(R_{i}, E_{i}\right) \leq 0\right]
$$


where $N$ in the number of simulations, $g($.$) is the failure function, I[$.$] is the function with$ value 1 , if the condition in the square bracket is fulfilled, otherwise is equal 0.

The most effective method is modified Latin Hypercube Sampling (LHS) method based on the simulations of the function $g($.) so thus MC method, but the definition domain of the distribution function $\Phi($.) is divided to $N$ intervals with the identical probability $1 / N$.

\section{Action effects to NPP structures}

The IAEA requirement $[1,5]$ proposes to calculus the structure for situations - test conditions, design accident conditions, service conditions and the extreme environmental conditions.

The load combination of the deterministic and probabilistic calculation is considered according to ENV 1990 [5] and IAEA [1] for the ultimate limit state of the structure. The load effect is defined as follows:

$\ni$ Deterministic method - extreme design situation

$$
E_{d}=\gamma_{g} G_{k}+\gamma_{q} Q_{k}+\gamma_{a} A_{k}
$$

\section{P Probabilistic method-extreme design situation}

$$
E=G+Q+A_{E}=g_{\mathrm{var}} G_{k}+q_{\mathrm{var}} Q_{k}+a_{\mathrm{var}} A_{E . k}
$$

where $G_{\mathrm{k}}$ is the characteristic value of the permanent dead loads, $Q_{\mathrm{k}}$ - the characteristic value of the permanent live loads, $A_{\mathrm{k}}$ - the characteristic value of the extreme loads, $\gamma_{\mathrm{g}}, \gamma_{\mathrm{q}}$, $\gamma_{\mathrm{a}}$ are the loading parameters $\left(\gamma_{\mathrm{g}}=\gamma_{\mathrm{q}}=\gamma_{\mathrm{a}}=1\right.$ for the extreme design situation), $g_{\mathrm{var}}, q_{\mathrm{var}}, a_{\mathrm{var}}$ are the variable parameters defined in the form of the histogram calibrated to the load combination in compliance with Eurocode and JCSS requirements [5].

\subsection{High confidence low probability of failure}

The concept of the HCLPF (High Confidence Low Probability Failure) capacity is used in the SMA (Seismic Margin Assessment) reviews to quantify the seismic margins of NPPs. In simple terms it corresponds to the earthquake level at which, with high confidence $(\geq$ $95 \%$ ) it is unlikely that failure of a system, structure or component required for safe shutdown of the plant will occur ( $<5 \%$ probability).

Estimating the HCLPF seismic capacity of a system, structure and component requires an estimation of the response, conditional on the occurrence of the RLE. Two candidate procedures to determine the $H C L P F$ seismic capacities for NPP's structures and equipment components have been developed:

- Fragility Analysis (FA), and

- Conservative Deterministic Failure Margin (CDFM) method.

The HCLPF approach or an equivalent method was used to verify the seismic capacity of NPP in Slovakia.

The value of the HCLPF parameter depends on the equipment structure or component resistance $(R)$ and the corresponding effect of action $(E)$ using elastic or inelastic behaviour.

The following equation follows for the strength and response $(R / E)$ in respect to linear elasticity

$$
(R / E)_{\mathrm{el}}=R /\left[\left(E_{\mathrm{Si}}^{2}+E_{\mathrm{Sa}}^{2}\right)^{1 / 2}+E_{0}\right]
$$


where $E_{\mathrm{Si}}$, or $E_{\mathrm{Sa}}$ is the seismic response to RLE (SL-2) inertial actions, or corresponding different seismic support movement, respectively, calculated according to linear elasticity. Then $E_{0}$ is a initial response to all the co-incidental non-seismic loads in the given combinations. Analogically, considering the elastic-plastic effect

$$
\left.(R / E)_{\mathrm{ep}}=R /\left\{\left[\left(E_{\mathrm{Si}} / k_{\mathrm{D}}\right)^{2}+\left(E_{\mathrm{Sa}} \cdot k_{\mathrm{D}}\right)^{2}\right]^{1 / 2}+E_{0}\right)\right\}
$$

where $k_{\mathrm{D}}$ is ductility coefficient $\left(k_{\mathrm{D}} \geq 1.0\right)$. The partial seismic response $E_{\mathrm{Ss}}$ in equation (6) is really multiplied, not divided, by the ductility coefficient. If SME is greater than RLE (SL-2), then $(R / E)_{\mathrm{ep}}$ is greater than 1.0 and vice-versa. However, the $(R / E)_{\mathrm{el}}$ and $(R / E)_{\mathrm{ep}}$ ratios do not define the multiplication factors for RLE (SL-2) to gain the HCLPF seismic margin value. These factors are calculated as follows

$$
\begin{gathered}
\left(F_{\mathrm{SF}}\right)_{\mathrm{el}}=\left(R-E_{0}\right) /\left(E_{\mathrm{Si}}{ }^{2}+E_{\mathrm{Sa}}{ }^{2}\right)^{1 / 2} \\
\left.\left(F_{\mathrm{SF}}\right)_{\mathrm{ep}}=\left(R-E_{0}\right) /\left(E_{\mathrm{Si}} / k_{\mathrm{D}}\right)^{2}+\left(E_{\mathrm{Sa}} \cdot k_{\mathrm{D}}\right)^{2}\right]^{1 / 2}
\end{gathered}
$$

where $E_{0}$ is a initial response to all the co-incidental non-seismic loads, $E_{\mathrm{Si}}$, or $E_{\mathrm{Sa}}$ is the seismic response to RLE (SL-2) inertial actions, or corresponding different seismic support movement, respectively, calculated according to linear elasticity, $k_{\mathrm{D}}$ is ductility coefficient $\left(k_{\mathrm{D}} \geq 1.0\right)$ corresponding the plastic capacity of the structural element and structural system in form

$$
k_{\mathrm{D}}=F_{\mu \mathrm{glob}} F_{\mu . \mathrm{loc}}
$$

where $F_{\mu \text {.glob }}$ is the global ductility factor depending on the structural system, $F_{\mu \text {.loc }}$ is local factor ductility depending on the type of the structural element and the reliability function (see [5]). Generally, it follows

$$
H C L P F(\mathrm{CDFM})=\left(F_{\mathrm{SF}}\right)_{\mathrm{ep}} \cdot P G A_{\mathrm{RLE}}
$$

and this value must always be $H C L P F>P G A$.

The HCLPF seismic margin value can also be determined via a non-linear elastic-plastic calculation (e.g. limit analysis defined in the ASME BPVC Section III - Mandatory Appendix XIII. ). Generally, such calculation needs to be repeated several times before the seismic margin value is reached. No ductility coefficient is used in these non-linear calculations, of course (ductility coefficients are used only in linear elastic calculations).

\section{Reliability margin of steel structures}

Reliability margin of steel structures was checked in accordance of national standards, Eurocodes and requirements of US NEA and the researchers' experience [5-9] on the ultimate limit state for median values of the effect of action and resistance. The failure function (1) for the linearized interaction diagram (Fig. 1) may be defined in the form

$$
g(N, M)=1-\left(N_{0}+F_{\mathrm{Sa}} N_{\mathrm{S}}\right) / N_{\mathrm{R}}-\left(M_{0}+F_{\mathrm{Sa}} M_{\mathrm{S}}\right) / M_{\mathrm{R}}=0
$$

where $N_{\mathrm{Ru}}$ and $M_{\mathrm{Ru}}$ are the values of limit normal force and moment on the axis of interaction diagram $N_{\mathrm{Ru}}=N_{\mathrm{R}}(M=0)$ and $M_{\mathrm{Ru}}=M_{\mathrm{R}}(N=0)$.

The total internal forces of the action effect are defined as follow

$$
M=M_{0}+M_{\mathrm{S}} \text { and } N=N_{0}+N_{\mathrm{S}}
$$


where $N_{0}, M_{0}$ are initial values of normal forces and moments due to no-seismic load and $N_{\mathrm{S}}, M_{\mathrm{S}}$ are normal forces and moments of the seismic load.

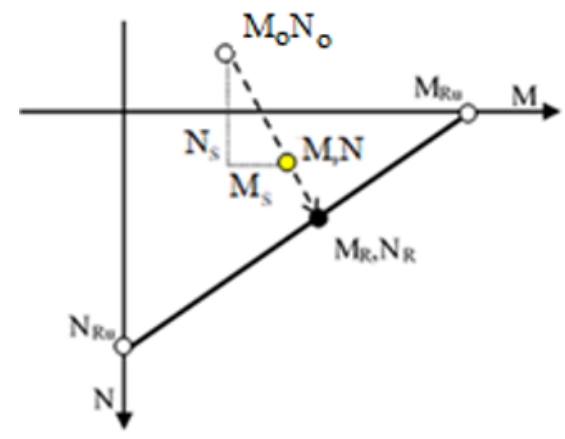

Fig. 1. Linearization of interaction diagram.

The moment of resistance $M_{\mathrm{R}}$ on the interaction diagram can be calculated from known normal force $N$ in the form

$$
M_{\mathrm{R}}=M_{\mathrm{Ru}}-\left(M_{\mathrm{Ru}} / N_{\mathrm{Ru}}\right) N
$$

The normal force $N$ on the interaction $\operatorname{diagram}\left(N=N_{\mathrm{R}}\right)$

$$
N_{\mathrm{R}}=\frac{M_{\mathrm{Ru}}-M_{0}+\left(M_{\mathrm{S}} / N_{\mathrm{S}}\right) N_{0}}{\left(M_{\mathrm{Ru}} / N_{\mathrm{Ru}}\right)+\left(M_{\mathrm{S}} / N_{\mathrm{S}}\right)}
$$

The safety factor $F_{\mathrm{SF} . \text { el }}$ can be expressed from (11), (13) and (14) as follows

$$
F_{S F . e l}=\left(N_{R}-N_{0}\right) / N_{S}=\left(\frac{M_{R u}-M_{0}+\left(M_{S} / N_{S}\right) N_{0}}{\left(M_{R u} / N_{R u}\right)+\left(M_{S} / N_{S}\right)}-N_{0}\right) / N_{S}
$$

\subsection{Seismic input data}

The seismic input data for EMO were taken from a specific study "Probabilistic analysis of seismic hazard for EMO NPP", [5], assessed by the IAEA in 2003 [1]. Two earthquake level SL-1 (for exceedance $10^{-3} /$ year) and SL-2 (for exceedance $10^{-4} /$ year) were considered.

The mean value of $P G A$ for SL-2 corresponds to $0.143 \mathrm{~g}$. Based on the recommendation of UJD SR, the mean $P G A$ value for SL-2 was chosen conservative as $0.15 \mathrm{~g}$. The spectrum shape was created based on the results of the PSHA study [1] and the sensitivity analysis [5] and corresponds to $84 \%$ NEP with 5\% damping. The vertical component is equal to $2 / 3$ of horizontal value, $P G A_{\text {vert }}=0.10 \mathrm{~g}$.

The comparison of the $P G A$ value and acceleration spectrum value for frequency $5 \mathrm{~Hz}$ for earthquake level SL-1 and SL-2 is presented in Fig. 2.

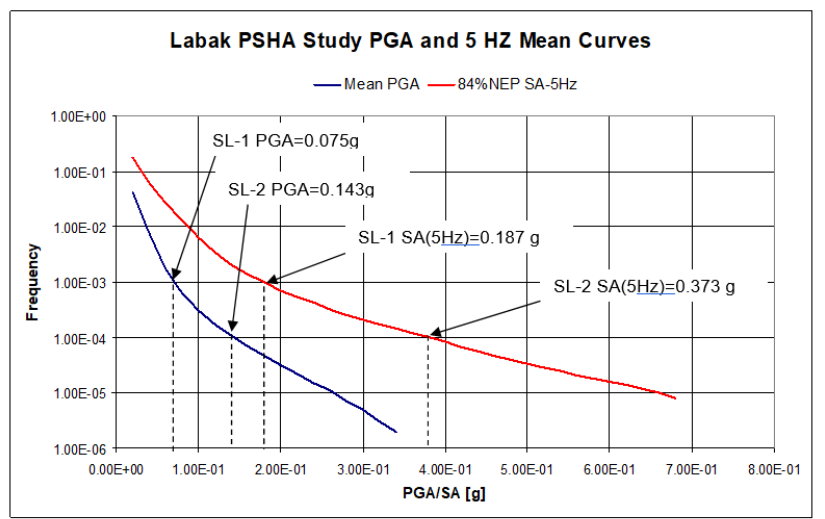

Fig. 2. The seismic risk curve for the mean value of $P G A$ and acceleration spectrum $S A$ for $5 \mathrm{~Hz}$.

The seismic response on the structures can be calculated in the frequency (spectrum 
response analysis) or time domain (transient analysis) [5]. The horizontal and vertical acceleration response spectrum at level SL-2 for the NEP (84.1\% probability), mean and median values considering 5\% damping are imagined in the Fig. 3.
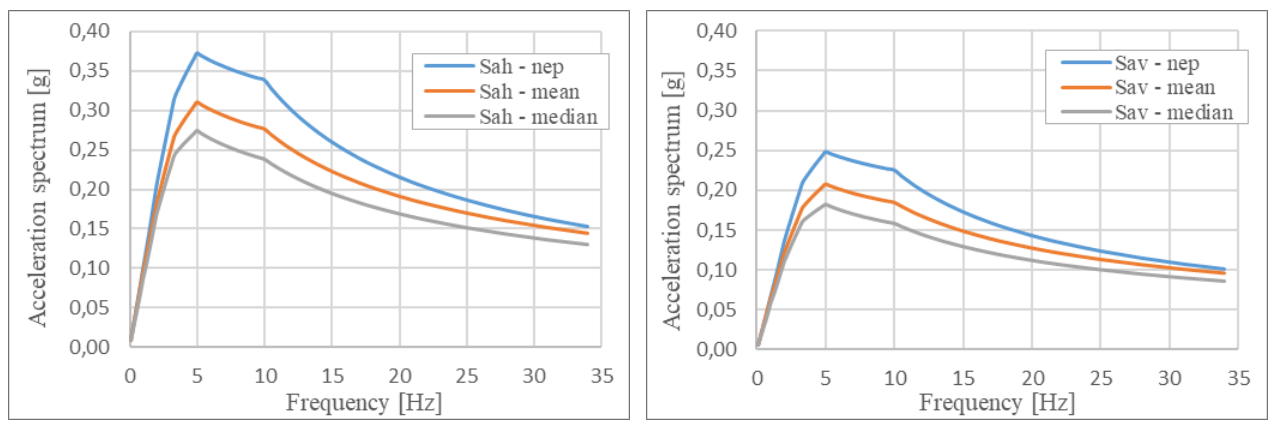

Fig. 3. Horizontal and vertical acceleration response spectrum for SL-2.

Also, hence the earthquake input was specified in the form of the response acceleration spectrum for spectral analyses [5]. The foundation of the reactor building NPP can be embedded into the rock subsoil.

\section{Calculation model of NPP structure}

The NPP WWER 440 building consists of six objects - reactor building, bubbler tower, airconditioning centre, turbine building, lengthwise side electrical building and cross side electrical building [5].

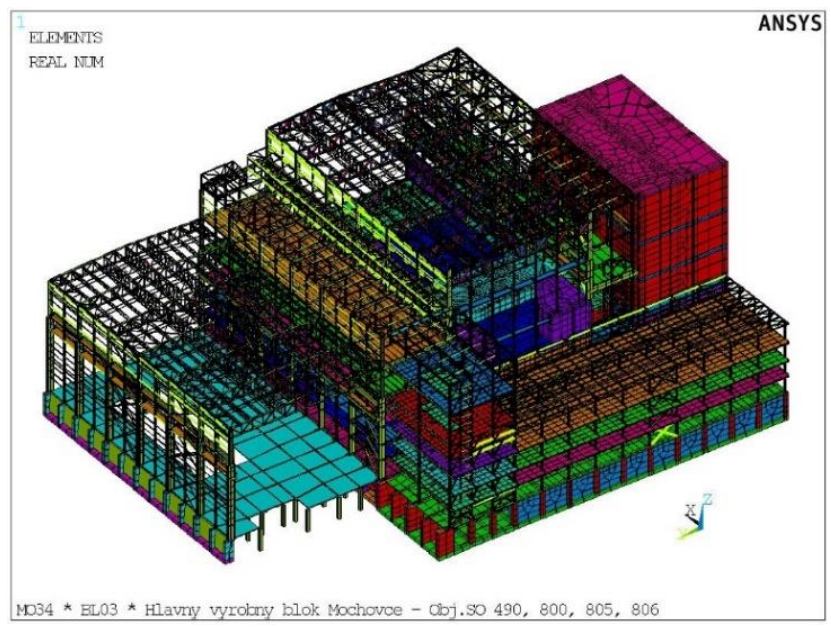

Fig. 4. Calculation model of NPP.

Table 1. Comparison of the modal analysis of various models.

\begin{tabular}{|l|r|c|c|c|c|c|c|c|}
\hline Model & \multirow{2}{*}{$\begin{array}{c}\text { No. of } \\
\text { elements }\end{array}$} & $\begin{array}{c}\text { Total } \\
\text { Mass } \\
\end{array}$ & & \multicolumn{2}{|c|}{ Direction - X } & \multicolumn{2}{c|}{ Direction - Y } & \multicolumn{2}{c|}{ Direction - Z } \\
\cline { 4 - 9 } & {$[\mathrm{t}]$} & $\begin{array}{c}\text { Freq. } \\
{[\mathrm{Hz}]}\end{array}$ & $\begin{array}{c}\text { Effect. } \\
\text { Mass [t] }\end{array}$ & $\begin{array}{c}\text { Freq. } \\
{[\mathrm{Hz}]}\end{array}$ & $\begin{array}{c}\text { Effect. Mass } \\
{[\mathrm{t}]}\end{array}$ & $\begin{array}{c}\text { Freq. } \\
{[\mathrm{Hz}]}\end{array}$ & $\begin{array}{c}\text { Effect. } \\
\text { Mass [t] }\end{array}$ \\
\hline ENEL & 1033992 & 241890 & 5.31 & 20533.90 & 3.35 & 6519.71 & 4.10 & 2363.25 \\
\hline EGP & 10612 & 244000 & 5.42 & 39537.90 & 3.80 & 31343.60 & 13.07 & 22903.30 \\
\hline STU & 162109 & 247200 & 5.23 & 23529.40 & 3.74 & 27817.80 & 12.76 & 36714.90 \\
\hline
\end{tabular}


The NPP building was discredited [5] by the 3D finite elements model to obtain realistic behaviour of structure, Fig. 4. The model (STU Bratislava) consists of 161856 elements with 440531 degrees of freedom. The drawbars are modelled by bilinear elements and contact between bubbler tower and air-conditioning centre by gap elements.

\section{Seismic resistance of NPP building}

On the base of SMA methodology the seismic resistance of the NPP structures in Slovakia was calculated. The recapitulation of the median value of the safety factor $F_{\text {SF.pl }}$ of principal structural elements of the NPP buildings in Mochovce is demonstrated in Table 2.

Table 2. The median value of the safety factor $F_{\mathrm{SF} . \mathrm{pl}}$ for NPP structural elements.

\begin{tabular}{|c|c|c|c|c|c|}
\hline $\begin{array}{c}\text { Columns } \\
\text { primary }\end{array}$ & $\begin{array}{c}\text { Vertical } \\
\text { bracing }\end{array}$ & $\begin{array}{c}\text { Horizontal } \\
\text { bracing }\end{array}$ & $\begin{array}{c}\text { Roof } \\
\text { truss }\end{array}$ & Beams & Anchors \\
\hline \multicolumn{7}{|c|}{ SO 490 Tools Hall } \\
\hline 1.87 & 2.53 & 2.54 & 4.87 & - & - \\
\hline \multicolumn{7}{|c|}{ SO 800 Reactor Hall } \\
\hline 2.33 & 2.40 & 2.07 & 4.73 & 2.67 & - \\
\hline \multicolumn{7}{|c|}{ SO 805 Longitude Gallery } \\
\hline 4.73 & 6.60 & 2.33 & 7.73 & 5.60 & 6.20 \\
\hline \multicolumn{7}{|c|}{ SO 806 Transversal Gallery } \\
\hline 3.87 & 2.33 & 9.40 & 8.73 & 5.67 & 6.33 \\
\hline
\end{tabular}

The seismic safety of NPP buildings is determined by the minimal safety factor under seismic load of the machine tool columns and horizontal bracing of reactor hall (see Table 2). The median value of the parameter $H C L P F$ is calculated from the relation (15) considering the median values of the action and resistance quantities. Then we have

$$
H C L P F_{50}=\left(F_{\mathrm{SF}}\right)_{\mathrm{ep}} \cdot P G A_{\mathrm{RLE}}=1.87 \times 0.15=0.28 \mathrm{~g}
$$

\section{Uncertainties of input data}

The uncertainties of the input data - action effect and resistance are for the case of the probabilistic calculation of the structure reliability defined in JCSS and Eurocode 1990 [5] (Table 3). The stiffness of the structure is determined with the characteristic value of Young's modulus $E_{\mathrm{k}}$ and variable factor $e_{\mathrm{var}}$. Loads are represented by their characteristic values $G_{\mathrm{k}}, Q_{\mathrm{k}}, A_{\mathrm{k}}$ and variable factors $g_{\mathrm{var}}, q_{\mathrm{var}}$ and $a_{\mathrm{var}}$. The resistance of the steel is delimited by the characteristic values of the strength $f_{\text {sk }}$ and the variable factor $f_{\text {var }}$. The uncertainties of the calculation model are considered by variable model factor $\theta_{\mathrm{R}}$ and variable load factor $\theta_{\mathrm{E}}$ for Gauss's normal distribution.

Table 3. The histograms of the input data.

\begin{tabular}{|l|c|c|l|c|c|}
\hline \multicolumn{2}{|c|}{ Quantities } & \multicolumn{3}{c|}{ Histograms } \\
\hline $\begin{array}{l}\text { Input } \\
\text { data }\end{array}$ & $\begin{array}{c}\text { Character. } \\
\text { value }\end{array}$ & $\begin{array}{c}\text { Variable } \\
\text { value }\end{array}$ & Type & $\begin{array}{c}\text { Mean } \\
\mu_{\mathrm{x}}\end{array}$ & $\begin{array}{c}\text { Deviation } \\
\sigma_{\mathrm{x}}\end{array}$ \\
\hline Dead load & $G_{\mathrm{k}}$ & $g_{\mathrm{var}}$ & Normal & 1.0 & 0.10 \\
Live load & $Q_{\mathrm{k}}$ & $q_{\mathrm{var}}$ & Gumbel & 0.6 & 0.21 \\
Seismic & $A_{\mathrm{k}}$ & $a_{\mathrm{var}}$ & Normal & 1.0 & 0.20 \\
Strength & $F_{\mathrm{k}}$ & $f_{\text {var }}$ & Lognormal & 1.0 & 0.10 \\
Modeling & $E_{\mathrm{k}}$ & $e_{\mathrm{var}}$ & Normal & 1.0 & 0.10 \\
Resistance & $R_{\mathrm{k}}$ & $r_{\mathrm{var}}$ & Normal & 1.0 & 0.08 \\
\hline
\end{tabular}


The probability of the structural failure was determined for the critical structural element on base of the deterministic analysis considering the median values of the action and resistance quantities and the uncertainties defined in form of the histograms (see Table 3).

\section{Fragility curve}

The fragility curve of the critical element is equal to the probability density function of parameter $H C L P F$ calculated from the median values of the action and resistance quantities and considering their uncertainties. On the base of the simulation methods in software FReET the failure load for the $5 \%$ and $50 \%$ probability of no-exceedance was determined as follows (Fig. 5).

$$
H C L P F_{50}=0.29 g \text { and } H C L P F_{05}=0.22 g
$$

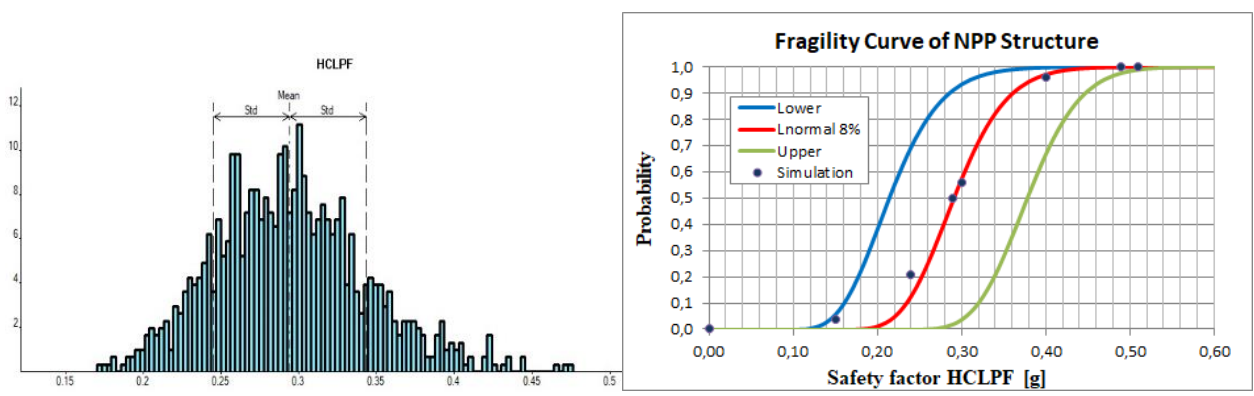

Fig. 5. Histogram and fragility curve of the failure function for the extreme seismic load.

\section{Conclusions}

This paper presented the deterministic and probabilistic methodology to analysis the seismic safety of NPP in Slovakia [3-5]. The methodology of the seismic re-evaluation of NPP in Slovakia is based on the new results from the geological and seismic-tectonic monitoring of this site. There were summarized the works performed by the IAEA in the areas of safety review. The calculation models and methods to determination of the fragility curve of the critical element of the NPP structure (Fig. 5). The results from this analysis present the international level of the seismic safety of the NPP structures in Slovakia.

The project was realized with the financial support of the Grant Agency of the Slovak Republic (VEGA). The project registration number is VEGA 1/0453/20.

\section{References}

1. IAEA, Safety Guide No. 28, Vienna (2003)

2. NUREG 0800, US NRC (2007)

3. J. Králik, M. Šimonovič, IMACS/Elsevier Science B.V. pp. 227-236 (1999)

4. J. Králik, J. Králik, jr. Engineering Structures, 31, 12, 2865 - 2872 (2009)

5. J. Králik, Monograph, (Ed. STU Bratislava, 307 pp., 2009)

6. M. Krejsa et al. Science Direct, Elsevier, 7, 228-235 (2016)

7. Z. Kala, Engineering Structures, 33, 8, 2342-2349 (2011)

8. V. Jaya et al. Journal of Structural Engineering (Madras), 38 (3), 217-229 (2011)

9. W. T. Lin et al. Advanced Science Letters, 8, 130-135 (2012) 